\title{
TINJAUAN PENERAPAN UNIT PENGOLAHAN DAN PEMASARAN BOKAR UNTUK MENDUKUNG GERAKAN BOKAR BERSIH DI SUMATERA SELATAN
}

\author{
The Implementation of Processing and Marketing Unit of Raw Rubber Material for Supporting Movement \\ of Clean Raw Rubber Material in South Sumatra \\ Aprizal Alamsyah, Iman Satra Nugraha, Dwi Shinta Agustina, dan Afrizal Vachlepi \\ Balai Penelitian Sembawa, Pusat Penelitian Karet \\ Jln. Raya Palembang - Betung KM 29, PO. BOX 1127 Palembang 30001 \\ Email : aprizal_alamsyah@yahoo.co.id
}

Diterima 8 Agustus 2016 / Direvisi 4 September 2017 / Disetujui 20 Oktober 2017

\begin{abstract}
Abstrak
Upaya perbaikan mutu bokar telah dilakukan pemerintah dengan menerbitkan peraturan menteri dan pedoman jaminan mutu karet. Kelembagaan di tingkat petani yang dikenal dengan UPPB bertujuan sebagai sarana bagi petani untuk meningkatkan mutu karetnya. UPPB memberikan manfaat, yaitu: adanya aturan yang disepakati secara musyawarah; meningkatnya mutu bokar petani melalui pemasaran bersama; meningkatkan posisi tawar bagi petani; dan media komunikasi petani agar dapat turut serta dalam program pengembangan karet rakyat. Namun masih banyak tantangan yang harus dihadapi antara lain modal usaha, komitmen anggota terhadap aturan yang berlaku, persaingan harga dengan tengkulak dan pedagang perantara, minimnya pengawasan terhadap mutu teknis pengolahan bokar, serta kurangnya pendampingan dalam pemasaran akibatnya minat petani lainnya untuk bergabung masih sedikit. Tulisan ini bertujuan untuk mengetahui dan memberikan gambaran penerapan UPPB, manfaat dan permasalahan yang dihadapi, serta dinamikanya dalam keberlangsungan mendukung gerakan nasional bokar bersih di Sumatera Selatan. Kajian ini menggunakan metode deskriptif untuk memperoleh gambaran tentang bagaimana penerapan UPPB. Hasil kajian menjelaskan bahwa
\end{abstract}

implementasi UPPB berdampak baik terhadap kondisi mutu bokar dan bagian harga petani, meskipun masih terdapat tantangan yang harus dihadapi. Untuk mendukung pengembangan industri karet alam nasional maka perlu dilakukan pendampingan terhadap UPPB, pelatihan dan pembinaan secara rutin yang melibatkan sebanyak mungkin anggota kelompok tani. Pentingnya implementasi rumusan-rumusan langkah tepat guna, pemberlakuan sanksi bagi tindak pelanggaran terhadap aturan dan penerapan bokar bersih juga harus dilakukan.

Kata kunci : bokar bersih, UPPB, gerakan nasional, kelompok tani.

\section{Abstract}

Efforts to improve the quality of raw rubber material have been conducted by the government by issuing of ministerial regulations and guidelines for quality assurance of rubber. Institution at the farmer level known as UPPB aims as a means for farmers to improve the quality of rubber. UPPB benefits, that is: the rules agreed by consensus; increasing the quality of farmers raw rubber material through joint marketing; improve bargaining position; to participate in smallholder rubber development program. But there are still many challenges to face such as business capital, member commitment to prevailing rules, price competition with brokers and middlemen, lack of supervision raw rubber material 
processing, and lack of marketing assistance resulting farmers to join is still small. This paper aims to know and provide an overview of UPPB implementation, the benefits and problems encountered, and dynamics in the continuity of supporting the national movement of clean raw rubber material in South Sumatra. This study uses descriptive method to get an idea of how UPPB is implemented. The results of the study explained that the implementation of UPPB had a good impact on the quality of raw rubber material and farmers share, although there are still challenges to be faced. To support the development of the national natural rubber industry it is necessary to provide assistance to $U P P B$, training and guidance on a regular basis that involves as many members of the group as possible. The importance of implementing the right step formulation for the enforcement of sanctions for violation of the rules and application of clean raw rubbermaterial must be done.

Keywords: raw rubber material, UPPB, national movement, farmers

\section{Pendahuluan}

Usaha peningkatan produktivitas kebun karet sudah berlangsung lama. Madjid (1995) mengemukakan bahwa kegiatan pemuliaan tanaman karet modern untuk mendapatkan produksi tinggi sangat diperlukan. Identifikasi klonal dan ciri-ciri vegetatifnya telah dilakukan sejak 1930an. Perkebunan besar negara maupun swasta telah melakukan efisiensi dan meningkatkan daya saing melalui optimalisasi produktivitas dengan menggunakan klon unggul baru (Nancy et al., 2001). Pengembangan karet rakyat menghendaki petani mandiri dan aktif memperbaiki serta meningkatkan produktivitas kebunnya melalui penerapan teknologi. Usaha pengembangan karet rakyat dalam perspektif perubahan bertujuan mengubah perilaku petani yang terwujud dalam bentuk tindakan berupa adopsi inovasi (Supriadi, 1990). Pada perkebunan rakyat adopsi benih klon karet unggul di Sumatera Selatan mencapai $67 \%$ (Syarifa et al., 2012) sampai di atas $85 \%$ (Permadi, 2014). Peningkatan produktivitas kebun karet akan memberikan keuntungan secara ekonomis dan mempengaruhi tumbuhkembangnya usaha makro-mikro di suatu wilayah.

Potensi produktivitas kebun karet mencapai $600-1.000 \mathrm{~kg} / \mathrm{ha} / \mathrm{th}$ pada perkebunan rakyat (Amir, 2015) dan 1.100 $1.800 \mathrm{~kg} / \mathrm{ha} /$ th pada perkebunan besar negara atau swasta (Rosyid, 2014; Direktorat Jenderal Perkebunan, 2015). Namun tingginya produktivitas kebun belum memberikan jaminan atas kondisi mutu bokar yang dihasilkan. Mutu bokar yang dihasilkan dari perkebunan rakyat ditentukan oleh perilaku petani dalam mengolah dan memasarkannya (Syarifa et al., 2010 \& Nancy et al., 2012).

Perbaikan mutu bokar tidak hanya membutuhkan teknologi melainkan perlu pendekatan yang efektif dan solusi informatif melalui peran pemerintah dan stakeholder terkait. Peranan lembaga pelaksana pembangunan perkebunan karet sangat mendukung kemajuan industri perkaretan di suatu negara. Keberadaan Lembaga Getah Malaysia sebagai salah satu pusat inovator pun masih memerlukan dukungan (implementing agency) seperti RISDA, FELDA, dan FELCRA dalam proses alih teknologi (Widyasari \& Supriadi, 2008).

Perhatian pemerintah terhadap industri perkaretan nasional berlangsung seiring terbentuknya kelompok/organisasi petani karet yang dirangsang melalui skema kebijakan yang menetapkan aturan main terkait mutu bokar. Lembaga maupun kelompok tani karet di berbagai wilayah sentra perkebunan karet telah ada sejak tahun 1980an sejalan dengan kelangsungan proyek pemerintah (Nancy et al., 1985). Terbentuk atas inisiatif anggota yang menginginkan adanya kelompok petani, belajar berorganisasi dan mendapatkan keuntungan lebih baik dengan berkelompok. Akan tetapi, dinamika yang terjadi dalam kelompok tani dapat terancam apabila tingkat kepercayaan dan pelayanan menurun sehingga perlu dilakukan pembinaan kelembagaan (Supriadi \& Nancy, 2001).

Tingkat adopsi teknologi di beberapa wilayah perkebunan karet khususnya di tingkat petani relatif masih rendah. Kondisi mutu bokar yang dihasilkan pun seringkali 
tidak memperhatikan standar persyaratan mutu yang baik berdasarkan SNI Bokar. Fungsi pengawasan pemerintah dalam meningkatkan produktivitas kebun belum berjalan seiring rencana pengembangan sektor hilir karet. Sekalipun begitu, pemerintah telah menetapkan kebijakan-kebijakan sebagai solusi untuk meminimalisir permasalahan yang dihadapi di industri perkaretan nasional.

Untuk memperbaiki mutu karet alam Indonesia, pemerintah telah menerapkan program "Gerakan Nasional Bokar Bersih atau GNBB". Gerakan Nasional Bokar Bersih sendiri merupakan suatu langkah yang diprogramkan pemerintah dengan melibatkan berbagai unsur lembaga dan petani karet (Wulandari, 2014, 2015). Gerakan Nasional Bokar Bersih Bokar Bersih dituangkan melalui peraturan Kementerian Pertanian (2008) No. 38/Permentan/OT.140/8/2008 tentang Pedoman Pengolahan dan Pemasaran Bahan Olah Karet, dan peraturan Kementerian Perdagangan (2009) No. 53/M DAG/PER/10/2009 tentang Pengawasan Mutu Bahan Olah Komoditi Ekspor Standard Indonesian Rubber yang diperdagangkan yang berlandaskan SNI yang diterbitkan oleh Badan Standardisasi Nasional (2002) No. 06-20472002 tetang bokar dan UU No.18 Tahun 2004 tentang Perkebunan.

Kebijakan bokar bersih bertujuan untuk : (1) Mendorong dan menggerakkan seluruh pemangku kepentingan untuk memperbaiki dan membangun kondisi mutu bokar yang selama ini belum teratasi dalam rangka mendukung peningkatan daya saing karet nasional; (2) Mengoptimalkan pemanfaatan sarana dan prasarana yang telah diberikan oleh Pemerintah; (3) Menghasilkan bokar bersih dan bermutu sesuai dengan persyaratan teknis dan atau standar mutu yang berlaku; (4) Memperbaiki dan meningkatkan nilai pendapatan masing-masing pihak yang terlibat secara proporsional dimulai dari tingkat penyiapan bokar, perdagangan domestik, industri pengolahan bokar hingga perdagangan ekspor; (5) Membantu memperkecil kerusakan fungsi lingkungan akibat pencemaran limbah cair dan bau dari proses penyiapan dan pengolahan karet.
Sementara itu, sasaran dari kebijakan bokar bersih adalah tercapainya persamaan persepsi, komitmen dan gerak langkah semua pemangku kepentingan untuk memperbaiki mutu bokar yang masih kurang baik; tersosialisasikannya peraturan-peraturan yang terkait dengan bokar bersih; teridentifikasinya Gapoktan yang telah mengelola Unit Pengolahan dan Pemasaran Bokar (UPPB); tercapainya optimalisasi penyediaan dan pemanfaatan sarana dan prasarana yang telah diberikan oleh pemerintah; dihasilkannya bokar yang bersih dan bermutu sesuai dengan permintaan pasar; tercapainya harga yang proporsional bagi petani; tercapainya peningkatan nilai daya saing karet nasional di pasar luar negeri; tercapainya keseimbangan lingkungan dengan memperkecil pencemaran limbah cair dan bau dari proses penyiapan dan pengolahan karet (Direktorat Jendral Perkebunan, 2013).

Dalam pelaksanaannya, Gerakan Nasional Bokar Bersih diarahkan melalui UPBB sebagai produsen bokar, baik itu UPPB yang baru dibentuk maupun kelompok/organisasi petani karet yang ditunjuk sebagai UPPB. Peran UPPB sangatlah penting, mengingat perilaku petani dipengaruhi beberapa faktor diluar pribadi yang mengikat individu secara emosional. Keterlibatan petani secara langsung dalam melakukan kegiatan pengolahan dan pemasaran bokar akan sangat dipengaruhi wawasan dan pengetahuan petani dalam memahami nilai-nilai yang terbentuk secara kolektif. Adanya UPPB dapat menjadi perantara pembinaan petani karet untuk selalu memproduksi bokar bersih dan bermutu baik.

Secara umum, eksistensi UPPB di wilayah sentra perkebunan rakyat akan sangat mendukung perbaikan mutu bokar di tingkat petani dan memberikan posisi tawar terhadap harga bokar bersih melalui pemasaran terorganisir. Meskipun begitu, masih terdapat permasalahan terkait modal, komitmen pengurus dan anggota, persaingan harga, dan pengawasan mutu serta minimnya pendampingan. Maka dari itu, untuk memperoleh informasi dan data sehingga memberikan gambaran UPPB secara lengkap, dilakukan pengamatan dan analisa secara 
deskriptif terhadap beberapa kelompok tani dan UPPB yang melakukan pemasaran terorganisir, meliputi tingkat adopsi teknologi, manfaat dan kendala yang dihadapi. Kajian ini diperlukan agar dapat memberikan masukan bagi kelompok pemasaran dan UPPB supaya dapat lebih optimal menjalankan fungsi kelembagaannya dan dalam rangka menguatkan peranan UPPB sesuai peraturan yang berlaku. Pada akhirnya tulisan ini bertujuan untuk mengetahui dan memberikan gambaran penerapan UPPB, manfaat dan permasalahan dalam penumbuhannya, serta dinamikanya dalam keberlangsungan mendukung gerakan nasional bokar bersih di Sumatera Selatan.

\section{Implementasi UPPB}

Unit pengolahan dan pemasaran bokar adalah unit usaha yang dibentuk oleh dua atau lebih kelompok pekebun untuk melakukan kegiatan bimbingan teknis, pengolahan dan pemasaran bokar. UPPB memiliki legalitas dengan adanya STR-UPPB yaitu surat tanda registrasi yang terdaftar di pemerintahan kabupaten/kota. Pemerintah harus memberikan bimbingan dan pembinaan terhadap UPPB. Terdapat beberapa hal yang melekat pada kelembagaan UPPB, diantaranya:

1. Setiap UPPB berhak menerbitkan dokumen tertulis berupa SKA (Surat Keterangan Asal) sebagai pelengkap administrasi dalam proses perdagangan bokar. SKA berisi nama, alamat pengolah, jenis bokar, berat timbangan dan kadar mutu.

2. Dibentuk oleh satu atau lebih kelompok pekebun.

3. Luasan kebun $\geq 100$ hektar, produksi lateks minimal $800 \mathrm{~kg}$ karet kering setiap 3 hari.

4. Memiliki fungsi pelayanan untuk kegiatan teknis dan pengembangan usaha.

5. Kepengurusan terdiri atas ketua, sekretaris dan bendahara (tidak diperkenankan dirangkap pengurus kelompok pekebun).

6. Memiliki AD/ART yang ditetapkan melalui musyawarah anggota.
7. Dilengkapi sarana kerja peralatan pengolahan (bak pembeku, hand-mangel, barak pengeringan, bahan pengumpal dan pengawet).

8. Terdapat tenaga teknis (anggota pekebun) yang terampil memberikan pelayanan dan pendampingan bagi pekebun dalam kegiatan pengolahan dan pemasaran bokar.

9. Memiliki aturan yang berlaku dan disepakati bersama terkait dengan pengelolaan UPPB.

10.Memiliki STR (surat tanda registrasi) yang diterbitkan oleh pemerintah terkait.

11.Membuat laporan berkala setiap 6 bulan berisikan jenis jumlah produksi, mutu, harga dan pembeli bokar.

12.Menjalin hubungan kerjasama dengan pabrik pengolahan bokar dalam bentuk kemitraan.

13.Menjalankan tugas dan mengatur pola kerjasama dalam pemasaran bokar.

14.Mendapatkan pembinaan secara intensif dari pemerintah kabupaten/kota atau instansi tertentu.

15. Mendapatkan pengawasan terkait dengan perdagangan dan peredaran bokar dari petugas khusus.

Sejak diterbitkannya PERMENTAN NO.

38 Tahun 2008, pemerintah telah mensosialisasikan Gerakan Nasional Bokar Bersih seiring dengan ditandai terbentuknya beberapa UPPB di wilayah sentra perkebunan karet rakyat, seperti di Sumatera Selatan, Jambi, Riau, dan Kalimantan Selatan. Pembentukan UPPB hingga saat ini masih tersebar di wilayah perkebunan rakyat yang memiliki potensi karet alam cukup besar (Tabel 1), dimana pada masing-masing wilayah campur tangan pemerintah setempat menjadi pendukung terbentuknya kelembagaan bagi petani karet.

Dalam upaya memperbaiki mutu karet dan revitalisasi perkebunan yang bertujuan untuk peningkatan daya saing karet alam serta mendukung Gerakan Nasional Bokar Bersih, setiap UPPB diberikan pedoman jaminan mutu. Pedoman penerapan sistem jaminan mutu bokar ini merupakan hasil perumusan Direktorat Jenderal Pengolahan dan 
Tabel 1. Jumlah UPPB di wilayah sentra perkebunan karet rakyat

\begin{tabular}{clc}
\hline Tahun & \multicolumn{1}{c}{ Provinsi (kabupaten/kota) } & UPPB \\
\hline 2017 & Sumatera Selatan & 147 \\
2017 & Jambi & 32 \\
2017 & Kalimantan Selatan & 100 \\
2016 & Sumatera Utara (Serdang Bedagai, Deli Serdang dan Tapanuli Selatan) & 3 \\
2014 & Riau & 33 \\
\hline
\end{tabular}

Sumber: data diolah dari (Putri, 2016; Gapkindo, 2017; Dinas Perkebunan Provinsi Sumatera Selatan, 2017; (data diolah)

Pemasaran Hasil Pertanian (P2HP) dalam rangka memfasilitasi UPPB untuk lebih memahami tugas dan fungsi operasionalnya secara kelembagaan. Namun, peran setiap anggota UPPB masih memerlukan bimbingan dan pengawasan secara intensif.

Pembinaan dari pemerintah yang diberikan secara berkelanjutan diperuntukkan bagi anggota UPPB yang aktif dan konsisten menjaga mutu karet. Selain mengikuti pelatihan mengenai budidaya tanaman karet dan bimbingan teknis untuk mendukung hilirisasi, UPPB juga didaftarkan untuk mendapatkan penyaluran sarana produksi. Keberadaan UPPB telah memberikan pengaruh positif dengan mengajak petani untuk mengubah perilaku atau kebiasaan mengolah bokar dan mendapatkan nilai tambah melalui pemasaran bersama. Maka dari itu, UPPB yang mandiri menjadi harapan untuk dapat bertindak selaku agen kontrol dalam masyarakat petani karet, turut berperan dalam perbaikan mutu karet nasional dan mendorong program Gerakan Nasional Bokar Bersih secara berkelanjutan.

\section{Manfaat Pembentukan UPPB}

Rendahnya harga karet di tingkat petani menyebabkan rendahnya pendapatan petani itu sendiri dan akan berdampak terhadap terhadap aktivitas ekonomi di pedesaan yang melemahkan daya beli masyarakat, khususnya petani. Syahza et al. (2015) menyatakan bahwa rendahnya posisi tawar (bargaining position) petani karet dengan pedagang ikut membantu rendahnya harga karet yang diterima oleh petani. Kondisi ini juga dipengaruhi oleh lemahnya kelembagaan petani karet.

Sistem pemasaran terorganisir melalui UPPB menjadi salah satu pilihan tepat bagi kelompok tani karet karena meningkatkan posisi tawar petani dan bagian harga petani. Keberadaan UPPB sama dengan keberadaan kelompok tani, Gapoktan dan koperasi karet yang tersebar di berbagai desa sentra karet rakyat. Seringkali kelembagaan kelompok tani karet/koperasi yang sudah berjalan aktif (mapan) dan melakukan pemasaran bersama juga dinyatakan sebagai UPPB yang terdaftar di setiap Dinas Perkebunan. Namun terdapat gabungan beberapa kelompok tani yang kemudian membentuk UPPB dengan memenuhi persyaratan sesuai dengan PERMENTAN No. 38 Tahun 2008.

UPPB telah menciptakan kesadaran petani untuk membuat bekuan sleb dengan tepat dan menggunakan pembeku anjuran, serta tidak lagi menambah bobot bekuan dengan cara merendam atau memasukan tatal. Ditetapkannya aturan dan kesepakatan mengenai mutu bokar menjadi prasyarat utama dilaksanakannya pemasaran bersama dan hal ini berlaku di setiap kelompok/ Gapoktan/koperasi dan UPPB. Pada Tabel 2 disajikan perbedaan mutu bokar petani yang dipasarkan secara tradisional dan terorganisir, yaitu dilihat dari aspek kebersihan, cara penyimpanan, jenis pembeku dan tempat yang digunakan.

Ketersediaan bahan baku yang didasarkan pada jumlah volume penjualan bokar melalui pemasaran bersama memberikan nilai tambah bagi eksistensi kelembagaan UPPB itu sendiri. 
Tabel 2. Perbandingan kualitas bokar petani tradisional dan terorganisir melalui UPPB

\begin{tabular}{llcc}
\hline & Uraian kriteria & $\begin{array}{c}\text { Tradisional (\%) } \\
(7 \text { desa })\end{array}$ & $\begin{array}{c}\text { Terorganisir (\%) } \\
(7 \text { UPPB) }\end{array}$ \\
\hline Kebersihan & Bersih & 5 & 100 \\
& Kotor & 95 & 0 \\
Penyimpanan & Tidak direndam & 0 & 100 \\
& Direndam & 100 & - \\
Jenis Pembeku & Asam Semut/Deorub & 0 & 82 \\
& Cuka Para & 98 & 18 \\
& Pupuk & 1 & 0 \\
& Tawas & 1 & 0 \\
Tempat Pembeku & Kotak Kayu & 70 & 100 \\
& Kotak Plastik & 25 & 0 \\
& Aluminium & 0 & 0 \\
\hline
\end{tabular}

Sumber: Primer, 2017 (data diolah)

Hal ini ditentukan dari jumlah anggota yang ikut dalam pemasaran bersama. Pengembangan pemasaran bersama melalui lelang ataupun tender biasanya dilakukan oleh kelompok dengan jumlah anggota bervariasi (minimal 25 orang). Sedangkan, UPPB dapat pula beranggotakan lebih dari satu kelompok. Jika diasumsikan masing-masing anggota memiliki 1 - 2 ha kebun karet, maka satu UPPB dapat menaungi 100 ha luasan kebun karet atau lebih. Volume penjualan bokar melalui kelembagaan kelompok/UPPB ini dapat mencapai 2,5-5 ton bokar per minggu atau per kegiatan lelang dengan keikutsertaan lebih dari 50 petani.

Koperasi atau UPPB memiliki susunan pengurus dan aturan yang disepakati agar kinerja organisasi dapat optimal. Selain dengan lelang dan tender pemasaran bersama yang dilakukan oleh UPPB adalah dengan kemitraan langsung ke pabrik. Dengan pola kemitraan UPPB dituntut secara konsisten menghasilkan produksi lebih dari $800 \mathrm{~kg}$ karet kering per tiga hari agar sistem pemasaran yang telah diterapkan berjalan efisien dan menguntungkan.
Pemasaran bersama yang dilakukan oleh UPPB merupakan pemasaran terorganisir sama halnya dengan kegiatan yang telah dilakukan beberapa kelompok/Gapoktan maupun koperasi melalui kemitraan dan pasar lelang. Pada Tabel 3 disajikan volume bokar di Sumatera Selatan yang dipasarkan melalui UPPB yaitu sekitar 87 ribu ton/tahun atau $8 \%$ dari volume bokar di Sumatera Selatan. Meskipun volume bokar yang diserap melalui pola pemasaran berkelompok ini masih sangat kecil, namun diharapkan ke depannya dapat terus ditingkatkan melalui pembinaan yang intensif oleh dinas-dinas terkait.

Kegiatan pasar lelang dan pola kemitraan yang diupayakan oleh kelompok/UPPB berdampak terhadap keseragaman mutu bokar yang diperdagangkan. Meskipun bahan pembekunya masih belum seluruhnya menggunakan asap cair tetapi cukup bersih, karena anggota kelompok dilarang mencampur dengan tatal dan sejenisnya. Sanksi diberikan kepada anggota yang tidak mengolah bokarnya sesuai dengan aturan yang disepakati oleh kelompok, yaitu tidak diterimanya bokar tersebut saat proses pemasaran bersama. Dengan menjaga mutu 
Tabel 3. Volume bokar melalui pemasaran bersama di Sumatera Selatan

\begin{tabular}{|c|c|c|c|c|}
\hline Kabupaten & $\begin{array}{l}\text { Tahun } \\
\text { berdiri }\end{array}$ & Nama kelompok/UPPB & Desa & $\begin{array}{l}\text { Volume bokar } \\
\text { per tahun (ton) }\end{array}$ \\
\hline \multirow{6}{*}{ Muara Enim } & 1988 & KUD Serasan Jaya & Gelumbang & 14.700 \\
\hline & 1988 & KUD Berkat & Lubuk Raman & 9.900 \\
\hline & 2003 & Bina Karya & Tanjung Raman & 4.100 \\
\hline & 2003 & KUD Panca Mulia & Sumber Rahayu & 3.700 \\
\hline & 2009 & Gapoktan Abadi Maju & Kencana Mulia & 250 \\
\hline & 2013 & Dibentuk $28 U P P B^{*}$ & & 14.040 \\
\hline \multirow{5}{*}{ Prabumulih } & 2000 & Manunggal Jaya & Kel Karang Jaya & 5.600 \\
\hline & 1988 & KUD Mufakat Jaya & Jungai & 2.800 \\
\hline & 2005 & Balam Sejahtera & Kel Patih Galung & 2.000 \\
\hline & 2003 & KUD Suka Maju & Tanjung Kemala & 1.400 \\
\hline & 2017 & Terdapat $2 U P P B^{*}$ & & $n / a$ \\
\hline Pali & 2017 & Terdapat $1 U P P B^{*}$ & & $n / a$ \\
\hline Lubuk Linggau & 2017 & Terdapat $4 U P P B^{*}$ & & $n / a$ \\
\hline Musi Banyuasin & 2017 & Terdapat $18 U P P B^{*}$ & & 4.500 \\
\hline Musi Rawas & 2017 & Terdapat $10 U P P B^{*}$ & & 713 \\
\hline Lahat & 2017 & Terdapat $2 U P P B^{*}$ & & $n / a$ \\
\hline OKU Timur & 2017 & Terdapat $2 U P P B^{*}$ & & $n / a$ \\
\hline \multirow[t]{2}{*}{ OKI } & 2017 & Terdapat 5 UPPB* & & 3.841 \\
\hline & 2010 & Ngerawan Indah & Seri Tanjung & 826 \\
\hline \multirow{3}{*}{ Ogan Ilir } & 1997 & Gapoktan Cahaya Bersinar & Tanjung Dayang & 350 \\
\hline & 1989 & KUD Wana Lestari & Payraman & 1.800 \\
\hline & 2017 & Terdapat $13 U P P B^{*}$ & & 5.448 \\
\hline \multirow{3}{*}{$\mathrm{OKU}$} & 2002 & Gapoktan Suka Maju & Bindu & 2.500 \\
\hline & 2017 & Terdapat $4 U P P B^{*}$ & & $n / a$ \\
\hline & 2009 & Gapoktan Harmas & Pelajau Ilir & 300 \\
\hline \multirow[t]{3}{*}{ Banyuasin } & 2009 & Lavender & Regan Agung & 200 \\
\hline & 2017 & Terdapat $43 U P P B^{*}$ & & 8.605 \\
\hline & & Jumlah (Slab) & & 87.574 \\
\hline
\end{tabular}

Sumber : Primer, 2017 (data diolah).

Keterangan: *UPPB yang terdaftar berdasarkan data Disbun Provinsi Sumatera Selatan

bokar sesuai standar, setiap anggota kelompok/UPPB akan memperoleh harga yang sama. Peningkatan kualitas bokar akan memberikan harga yang lebih.

Setiap petani yang bergabung dan ikut dalam UPPB akan mendapatkan keuntungan karena UPPB tersebut memberikan jaminan ketersediaan pasokan bokar dengan mutu yang terjaga secara baik. Proses pelelangan maupun kemitraan yang dijembatani oleh UPPB ke pabrik menjadi kunci keberhasilan pemasaran bersama. Pengamatan fisik bokar masih dilakukan secara visual oleh pedagang maupun perwakilan pabrik, akan tetapi harga yang diterima petani UPPB lebih baik karena mutu bokar dan posisi tawar dalam pemasaran bersama. Pemasaran bersama telah dapat meningkatkan bagian harga yang diterima petani sebesar 83 - >90\% FOB (Tabel 4). Presentase FOB yang diterima petani diperoleh dengan mengetahui mutu bokar mingguan dan bulanan. Pengamatan telah dilakukan pada kelompok pemasaran terorganisir dan membandingkannya dengan pemasaran yang dilakukan petani secara tradisional di satu wilayah desa yang sama.

Secara kelembagaan UPPB telah memberikan manfaat yang banyak menguntungkan kelompok tani dan juga anggotanya. Selain meningkatkan kualitas 
Tabel 4. Perbandingan harga yang diterima petani melalui pemasaran bersama

\begin{tabular}{|c|c|c|c|}
\hline Sistem pemasaran & Jenis bokar & $\begin{array}{l}\text { Harga petani } \\
(\% \text { FOB })\end{array}$ & Tahun penelitian \\
\hline \multicolumn{4}{|l|}{ 1. Tradisional } \\
\hline Lokasi jauh & Slab Tebal & $55-70$ & 2000 \\
\hline Lokasi dekat & Slab Tebal & $70-80$ & 2000 \\
\hline \multicolumn{4}{|l|}{ Terorganisir/pemasaran bersama } \\
\hline Lelang informal (Batumarta, OKU) & Slab Tebal & 83 & 2000 \\
\hline Pampangan (OKI) & Slab Tebal & 83 & 2000 \\
\hline KUD Serasan & Slab Tipis & $>90$ & \\
\hline KUD Berkat & Slab Tipis & $>90$ & \\
\hline KUD Mufakat & Slab Tipis & $>90$ & 2012 \\
\hline
\end{tabular}

Sumber: Nancy et al. (2012)

mutu bokar dan petani menerima bagian harga yang lebih baik, serta adanya peluang bagi kelompok UPPB untuk menerima penyaluran bantuan dari pemerintah dan stakeholder lainnya. Maka dalam kaitannya dengan adanya tata niaga bokar yang berlangsung saat ini, keberadaan UPPB berhasil mempersingkat mata rantai pemasaran baik melalui kemitraan ataupun penawaran langsung pihak pabrik pengolahan melalui kegiatan lelang bokar. Penyelenggaraan tata niaga bokar berkualitas melalui UPPB menjadi pilihan dan ketetapan pemerintah Kabupaten Tanah Bumbu, Kalimantan Selatan, dukungan pemerintah setempat diupayakan dengan adanya Peraturan Bupati Tanah Bumbu No. 23 Tahun 2016 (Noor, 2016; Kabupaten Tanah Bumbu, 2016).

\section{Teknologi Pengolahan Bokar Bersih}

Pengolahan bahan olah karet (bokar) merupakan salah satu tahapan penting dalam rangkaian proses pengolahan karet alam. Kegiatan ini akan menentukan mutu produk ekspor karet Indonesia yang didominasi SIR 20. Bahan baku utama memproduksi SIR 20 berasal dari bokar petani. Untuk menghasilkan karet remah yang bermutu baik, penerapan teknologi pengolahan bokar yang bersih dan baik harus dilakukan oleh petani. Bokar yang bersih dan bermutu baik berdasarkan Standar Nasional Indonesia (SNI) No. 06-2047-2002 tentang bahan olah karet (Tabel 5).
Seperti terlihat pada Tabel 5, jenis bokar yang tercantum dalam SNI tersebut terdiri atas lateks kebun dan koagulum berupa sit, slab dan lump. Dari ketiga jenis bokar tersebut, slab dan lump merupakan jenis bokar yang paling banyak diproduksi dan diperjual-belikan di tingkat petani terutama di Provinsi Sumatera Selatan. Dalam SNI tersebut, slab dan lump yang bermutu baik harus memenuhi persyaratan mutu untuk parameter ketebalan, kebersihan dan jenis koagulan yang digunakan.

Persyaratan parameter ketebalan bokar slab dibedakan menjadi 4 (empat) jenis mutu, yaitu mutu I dengan ketebalan $<50 \mathrm{~mm}$, mutu II (51-100), mutu III (101-150) dan mutu IV untuk bokar dengan ketebalan lebih dari 150 $\mathrm{mm}$. Untuk kebersihan, SNI tersebut mensyaratkan bokar yang bermutu baik harus bersih atau tidak terdapat kotoran. Sedangkan untuk penggunaan bahan penggumpal, bokar tersebut harus digumpalkan menggunakan bahan penggumpal asam semut dan bahan lain yang tidak merusak mutu karet serta penggumpalan alami. Bahan penggumpal lain yang dimaksudkan dalam SNI ini adalah bahan penggumpal yang direkomendasikan Pusat Penelitian Karet.

Bahan penggumpal yang dianjurkan adalah asap cair dan formulanya. Koagulan asap cair akan menghasilkan karet bermutu baik dan sifat-sifat teknis yang baik (Solichin et al., 2007). Asap cair sendiri merupakan cairan berwarna cokelat dengan $\mathrm{pH}$ sekitar 2,5-3,0 
Tabel 5.Perbandingan mutu bokar (slab) berdasarkan SNI No. 06-2047-2002 dan hasil olahan UPPB

\begin{tabular}{|c|c|c|c|c|c|c|}
\hline \multirow[b]{2}{*}{ Jenis uji/parameter } & \multirow[b]{2}{*}{ Satuan } & \multirow{2}{*}{$\begin{array}{l}\text { Lateks } \\
\text { kebun }\end{array}$} & \multicolumn{4}{|c|}{ Perbandingan } \\
\hline & & & Sit & $\begin{array}{l}\text { Slab } \\
(\mathrm{SNI})\end{array}$ & $\begin{array}{c}\text { Slab } \\
(\mathrm{UPPB})\end{array}$ & Lump \\
\hline Kadar karet kering & & & & & & \\
\hline - Mutu I & $\%$ & 28 & - & - & - & - \\
\hline - Mutu II & $\%$ & 20 & - & - & - & - \\
\hline Ketebalan (T) & & & & & & \\
\hline - Mutu I & $\mathrm{mm}$ & - & 3 & $<50$ & - & 50 \\
\hline - Mutu II & $\mathrm{mm}$ & - & 5 & $51-100$ & - & 100 \\
\hline - Mutu III & $\mathrm{mm}$ & - & 10 & $101-150$ & - & 150 \\
\hline - Mutu IV & $\mathrm{mm}$ & - & - & $>150$ & $>150$ & $>150$ \\
\hline Kebersihan (B) & - & - & $\begin{array}{l}\text { Tidak } \\
\text { terdapat } \\
\text { kotoran }\end{array}$ & $\begin{array}{c}\text { Tidak terdapat } \\
\text { kotoran }\end{array}$ & $\begin{array}{c}\text { Tidak } \\
\text { terdapat } \\
\text { kotoran }\end{array}$ & $\begin{array}{c}\text { Tidak terdapat } \\
\text { kotoran }\end{array}$ \\
\hline Jenis Koagulan & - & - & $\begin{array}{l}\text { Asam semut } \\
\text { dan bahan } \\
\text { lain yang } \\
\text { tidak } \\
\text { merusak } \\
\text { mutu karet }^{\star} \text { ) }\end{array}$ & $\begin{array}{c}\text { Asam semut } \\
\text { dan bahan lain } \\
\text { yang tidak } \\
\text { merusak mutu } \\
\text { karet }^{*} \text { ), serta } \\
\text { penggumpalan } \\
\text { alami }\end{array}$ & $\begin{array}{c}\text { Asam } \\
\text { semut dan } \\
\text { deorub }\end{array}$ & $\begin{array}{c}\text { Asam semut } \\
\text { dan bahan lain } \\
\text { yang tidak } \\
\text { merusak mutu } \\
\text { karet }^{*} \text { ), serta } \\
\text { penggumpalan } \\
\text { alami }\end{array}$ \\
\hline
\end{tabular}

yang dihasilkan dari proses pirolisis cangkang sawit. Aplikasi asap cair dan formulanya sebagai bahan penggumpal akan menghasilkan karet bermutu baik dan tidak berbau busuk (Vachlepi \& Solichin, 2008).

Untuk di tingkat petani, aplikasi bahan penggumpal anjuran baik itu asam semut maupun asap cair dapat dilakukan dengan dua cara, yaitu pada penggumpalan lateks di mangkok sadap dan di bak penggumpal untuk mencetak/membuat sleb lum. Bak penggumpal yang digunakan umumnya berukuran sekitar $60 \mathrm{~cm}$ x $40 \mathrm{~cm}$ x $15 \mathrm{~cm}$ agar bokar sleb yang dihasilkan masuk ke dalam mutu I sampai mutu III. Untuk menjaga kebersihan bokar, pada saat proses pencetakan atau pembuatan sleb perlu dilakukan pembersihan dari kontaminan berupa bahanbahan bukan karet. Beberapa kontaminan yang ditemukan dalam bokar petani antara lain daun, tatal, pasir, dan lumpur. Keberadaan kontaminan ini selain merusak mutu karet juga berdampak pada semakin panjangnya rantai proses pengolahan yang harus dilakukan terutama proses pembersihan. Akibatnya biaya produksi menjadi tinggi dan mutu karet Indonesia menjadi kurang baik. Biaya produksi yang tinggi ini akan berdampak pada rendahnya harga yang diterima petani karet. Dengan memproduksi dan memperjualbelikan bokar yang bersih dan bermutu baik (sesuai SNI), biaya produksi dapat ditekan dan efisiensi biaya tersebut harapannya dapat dikembalikan ke petani dalam bentuk harga yang lebih baik.

\section{Permasalahan dan Tindak Lanjut UPPB}

UPPB memiliki fungsi secara kelembagaan untuk memfasilitasi kebutuhan anggotanya dalam hal pemberian layanan kegiatan teknis dan melakukan kegiatan pengembangan unitunit usaha. Upaya lain yang dilakukan UPPB sebagai suatu lembaga bagi petani karet adalah adanya suatu bentuk tanggungjawab terhadap alih teknologi karet. Alih teknologi ini 
terlaksana melalui partisipasi aktif anggota UPPB dan peran pengurus untuk mentransfer teknologi. Bernard et al. (2010) mengungkap bahwa petani yang tergabung dalam kelompok tani lebih mudah diyakinkan untuk mengadopsi teknologi dibandingkan dengan petani perseorangan. Najiyati et al. (2012) mengemukakan peranan kelembagaan atau kelompok dalam masyarakat diantaranya sebagai sarana pembelajaran yang efektif dan sarana untuk membangun hubungan kemitraan dalam suatu proses difusi teknologi dengan berbagai media/sarana komunikasi.

Perbaikan mutu bahan olah karet di tingkat petani menjadi tujuan utama Gerakan Nasional Bokar Bersih. Pembentukan UPPB hingga saat ini terus diupayakan sekalipun dalam perjalanannya masih banyak menghadapi kendala. Beberapa permasalahan yang dihadapi oleh UPPB antara lain sikap petani yang tidak peduli akan standar yang diberlakukan, kurangnya pengetahuan mengenai standar nasional mutu bokar. Lemahnya modal ekonomi dianggap sebagian besar petani akan mempengaruhi kegiatannya dalam aplikasi teknologi (Biba, 2016). Minimnya pengetahuan petani juga beralasan, keterbatasan modal seringkali menjadi penyebab di mana petani harus cermat dalam menentukan prioritas pekerjaan untuk memenuhi kebutuhan sehari-hari dibandingkan meluangkan waktu untuk mengadopsi teknologi yang dianjurkan. Menurut Testiana (2010) tingkat pendidikan memiliki pengaruh positif terhadap keputusan petani karet dalam mengikuti program revitalisasi perkebunan, salah satu program yang mendukung Gerakan Nasional Bokar Bersih. Kondisi sosial ekonomi petani karet yang bermukim di pedesaan dan lokasi kebun yang sebagian besar tidak didukung dengan infrastruktur jalan yang baik menjadi kendala yang belum terselesaikan.

Terdapat tantangan pada masing-masing pihak terkait dalam mengembangkan proses pengolahan dan pemasaran bokar bersih melalui UPPB. Pemerintah selaku penentu arah dan kebijakan telah menetapkan peraturan sejalan dengan Gerakan Nasional
Bokar Bersih dalam upaya peningkatan daya saing karet nasional (Syarifa et al., 2013). Selain itu, tanggung jawab sosialisasi dan berkoordinasi dalam membina kelompok/Gapoktan telah dilakukan melalui berbagai program pengembangan dan pemberdayaan kelompok. Dinamika organisasi yang terjadi antara kelompok dan atau Gapoktan pada kelembagaan UPPB berlangsung dalam hal teknis pengolahan, pemasaran dan pengawan mutu. Adanya persyaratan administrasi dan ketentuan teknis yang diselenggarakan seringkali belum berjalan lancar sesuai yang diharapkan, alur kegiatan UPPB dapat dilihat pada Gambar 1.

Adapun perihal yang dapat dijadikan fokus permasalahan dalam upaya mendukung keberlanjutan Gerakan Nasional Bokar Bersih dapat dilihat dalam dua sisi sudut pandang. Pertama dari sisi permasalahan, masih terdapat beberapa kelemahan yang mempengaruhi penerapan UPPB, diantaranya

Partisipasi petani untuk bergabung di UPPB dipengaruhi oleh tingkat kesadaran dan kemauan untuk mengubah perilaku mengolah bokar bersih sesuai dengan teknologi yang direkomendasikan dan keterbatasan modal petani.

Komitmen pengurus UPPB dalam memberikan pelayanan terhadap anggotanya, seringkali kelangsungan pemasaran bersama berjalan dengan baik apabila pengurus mampu memberikan jaminan pembeli bokar langsung dari pihak pabrik. Pengurus UPPB harus berperan aktif dan menjembatani jejaring dengan stakeholder.

Dukungan dalam bentuk pendampingan, pembinaan melalui pelatihan/bimtek dari dinas pertanian/perkebunan dan dinas perdagangan serta pemerintah setempat menjadi penting. Fungsi pengawasan dan pemberlakuan sanksi terhadap proses alur tata niaga bokar sesuai aturan berdasarkan Permentan No. 38 Tahun 2008 belum maksimal diselenggarakan. 


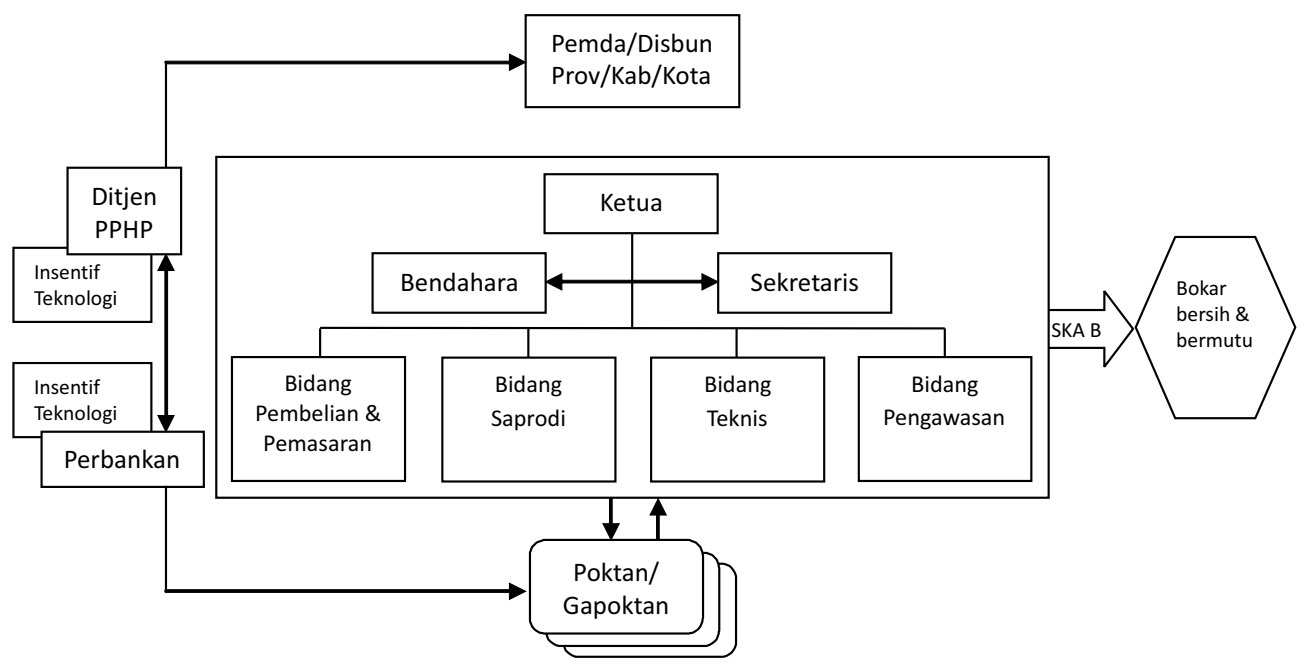

Sumber : (Direktorat Jenderal Pengolahan dan Pemasaran Hasil Pertanian, 2011; Aresyanto, 2015)

Gambar 1. Alur struktur organisasi UPPB

Sementara itu, untuk mengatasi kelemahan yang dialami, maka perlu dilakukan kajian mendalam untuk menjawab tantangan dari tengkulak dalam rantai pemasaran yang kompleks, persaingan harga yang mempengaruhi keputusan petani menjual bokar. Mengatasi problema pendistribusian bantuan saprodi ke petani anggota kelompok UPPB agar lebih selektif, tepat sasaran dan merata serta adanya peningkatan volume kegiatan dalam upaya penumbuhan dan penguatan UPPB agar lebih tepat guna dan inovatif.

Keterbatasan akses informasi tingkat petani sehingga perlu tenaga ahli yang memiliki kompetensi diusahatani karet dan berintegritas terhadap kemajuan industri karet nasional sebagai jaringan dalam UPPB juga sangat dibutuhkan. Perbedaan aturan antar pabrik yang menjadi ketetapan pabrik pengolahan karet remah terhadap stok bahan baku yang diperoleh. Beberapa pabrik masih menerima bahan baku karet kotor dengan alasan untuk memenuhi kapasitas produksi.

Permasalahan yang dihadapi sangat perlu dievaluasi karena adanya kegiatan dari serangkaian program yang telah terlaksana. Sementara untuk hal lainnya permasalahan yang cenderung menjadi kendala dalam keberlanjutan program GNBB dan tumbuh- kembangnya UPPB biasanya berkaitan dengan pemilik modal dan pengambil kebijakan. Pemerintah belum optimal melakukan pembinaan dan pengawasan huluhilir industri karet alam.

UPPB dapat terus eksis selama pengurus dan anggotanya konsisten untuk mengupayakan perbaikan mutu bokar. Akan tetapi, ketidak-seimbangan jumlah atau keberadaan UPPB di beberapa wilayah sentra terhadap luasan kebun karet tentu akan menghambat laju perbaikan mutu karet alam nasional. Sehingga sangat perlu UPPB mendapatkan pendampingan dalam hal memberikan pelayanan kegiatan teknis dan pengembangan usaha secara berkala dari kerjasama pemerintah dan stakeholder terkait perkaretan.

\section{Perlunya Peraturan Daerah dan Pemberlakuan Sanksi}

Pengawasan terhadap segala bentuk upaya dalam mendukung perbaikan mutu karet alam menjadi kegiatan wajib yang harus direncanakan sedemikian rupa untuk meningkatkan hasil dan produktivitas industri karet alam. Pencapaian target dari program Gerakan Nasional Bokar Bersih yang telah dilakukan seharusnya dievaluasi sehubungan 
dengan perubahan mendasar perilaku tani/kelompok dari kegiatan budidaya dan pengolahan sampai ke pemasaran di tingkat petani. Kebijakan yang menjadi dasar pelaksanaan program Gerakan Nasional Bokar Bersih dalam bentuk peraturan dan ketetapan masih harus didukung dengan tugas dan tanggung jawab pemerintah setempat yang wilayah administrasinya merupakan sentra perkebunan rakyat. Pemerintah daerah sebagaimana dinyatakan dalam peraturan menteri pertanian tentang UPPB, dituntut ikut berperan dalam hal membina dan mengawasi kegiatan terkait dengan pengolahan dan pemasaran bokar di wilayahnya. Peraturan daerah dimaksudkan untuk memberikan pedoman aturan pengelolaan karet alam di wilayah masing-masing dari sektor hulu hingga hilirnya. Peraturan daerah yang menjadi pedoman dalam pengawasan kelangsungan kegiatan proses pengolahan hingga pemasaran bokar yang beredar.

Penerapan sanksi atas segala bentuk pelanggaran yang mengakibatkan kerugian finansial maupun fisik terkait mutu bokar menurut standar harus diawasi pula pelaksanaannya. Pemberlakuan sanksi ini merupakan suatu langkah konkrit agar masing-masing pihak baik pekebun, pedagang maupun di tingkat pabrik pengolahan merasakan efek jera untuk tidak menyalahi peraturan yang berlaku. Untuk itu, pemerintah di daerah masing-masing perlu membentuk suatu tim yang memiliki tugas dan bekerja menjalankan fungsi pembinaan dan pengawasan. Apabila kegiatan tersebut dilakukan tepat sasaran maka program pengembangan karet alam dan perbaikan mutu dapat tercapai.

\section{Kesimpulan}

Penerapan UPPB di beberapa wilayah sentra perkebunan karet di Sumatera Selatan turut serta mengefisienkan tata niaga pemasaran bokar. Secara umum UPPB memberikan manfaat berupa peningkatan mutu bokar petani lebih seragam dengan pe $n g g u n$ a $n$ pembeku yang direkomendasikan, berupa asam semut atau deorub, tumbuhnya kesadaran di tingkat petani untuk menjaga mutu bokar; peningkatan bagian harga yang diterima petani dengan posisi tawar petani yang lebih baik, menambah pendapatan petani; peningkatan pengetahuan dan keterampilan (transfer teknologi) di tingkat petani dalam budidaya dan pengolahan bokar sesuai dengan teknologi yang dianjurkan. Selain itu, terdapat pula beberapa hal yang menjadi perhatian dalam penerapan UPPB, seperti halnya persaingan harga dengan tengkulak dan minimnya sarana dan prasarana pendukung kegiatan pengolahan dan pemasaran. Perlunya regulasi terkait pembelian bokar bersih oleh pihak pabrik dan pemberlakuan sanksi bagi pelanggaran peraturan yang ditetapkan. Pemerintah dan dinas terkait berperan penting dalam menunjang eksistensi UPPB melalui pendampingan/pemberdayaan kelompok UPPB, pengawalan teknis ataupun transfer teknologi terapan yang inovatif.

\section{Daftar Pustaka}

Amir, A. S. (2015, Januari). Pabrik karet kesulitan bahan baku. Media Perkebunan, 50-51.

Aresyanto. (2015). Kelembagaan unit pengolahan dan pemasaran bahan olah karet (UPPB). Retrieved from Dinas Kehutanan dan Perkebunan, Kabupaten Barito Timur.

Badan Standardisasi Nasional. (2002). SNI 062047-2002 tentang bahan olah karet. Jakarta: Badan Standardisasi Nasional.

Bernard, M., Hellin, J., Nyikal, R., \& Mburu, J. (2010, 16 September). Determinants for use of certified maize seed and the relative importance of transaction costs. Paper presented at the Joint 3rd African Association of Agricultural Economists (AAAE) and 48th Economists Agricultural Association of South Africa (AEASA) Conference, Cape Town 
Biba, M. A. (2016). Preferensi Petani terhadap Jagung Hibrida Berdasarkan Karakter Agronomik, Produktivitas, dan Keuntungan Usahatani. Jurnal Penelitian Pertanian Tanaman Pangan, 35(1), 81-88.

Direktorat Jenderal Pengolahan dan Pemasaran Hasil Pertanian. (2011). Pedoman penerapan sistem jaminan mutu BOKAR. Jakarta: Kementerian Pertanian.

Direktorat Jenderal Perkebunan. (2015). Statistik perkebunan Indonesia: Karet 2014 2016. Jakarta, Indonesia: Direktorat Jenderal Perkebunan, Kementerian Pertanian. .

Direktorat Jendral Perkebunan. (2013). Bokar bersih meningkatkan daya saing. http://ditjenbun.pertanian.go.id Retrieved from http://ditjenbun.pertanian.go.id

Kabupaten Tanah Bumbu. (2016). Peraturan bupati tanah tumbu Nomor 23 Tahun 2016 : Peningkatan mutu bahan olah karet melalui penataan dan penguatan kelembagaan kelompok tani. Kabupaten Tanah Bumbu: Pemerintah Kabupaten Tanah Bumbu.

Kementerian Perdagangan. (2009). Peraturan menteri perdagangan RI No.53 tahun 2009 tentang pengawasan mutu bahan olah komoditi ekspor standard Indonesian rubber yang diperdagangkan. Jakarta: Kementerian Perdagangan.

Kementerian Pertanian. (2008). Peraturan menteri pertanian RI No.38 tahun 2008 tentang pedoman pengolahan dan pemasaran bahan olah karet. Jakarta: Kementerian Pertanian.

Madjid, A. (1995). Mengenal klon-klon karet dalam setengah abad karet Indonesia mengisi kemerdekaan. Jakarta, Indonesia: Gapkindo.

Najiyati, S., Danarti, Murdiatun, Damanik, L., Slamet, R. T. S., \& Suwardin, D. (2012). Difusi teknologi pengolahan karet rakyat di kawasan transmigrasi mendukung koridor ekonomi Sumatera. Jurnal Ketransmigrasian, 29(1), 23-31.
Nancy, C., Effendi, S., \& Muharminto. (1985). Penelaahan terhadap petani peserta proyek PRPTE: studi kasus di kecamatan banyuasin III, Muba, Sumatera Selatan: Laporan Penelitian Retrieved from Balai Penelitian Sembawa, Banyuasin.

Nancy, C., Supriadi, M., Amypalupy, K., \& Anwar, R. (2001, 5-6 November). Sistem penyediaan dan penyebaran benih klon karet unggul untuk perusahaan perkebunan dan perkebunan karet rakyat. Paper presented at the Lokakarya Nasional Pemuliaan Karet 2001, Palembang.

Nancy, C., Syarifa, L. F., Agustina, D. S., Alamsyah, A., \& Nugraha, I. S. (2012). Buku Pengembangan pemasaran bahan olah karet di Provinsi Sumatera Selatan. Banyuasin, Indonesia: Dinas Perkebunan Provinsi Sumatera Selatan dan Balai Penelitian Sembawa.

Noor, M. (2016, 8 Agustus). Tingkatkan ekonomi petani karet melalui UPPB. Bidik Kalsel. Retrieved from http://www.bidikkalsel.com/2016/08/tin gkatkan-ekonomi-petani-karetmelalui.html.

Permadi, P. (2014, Oktober). Kiat meningkatkan produktivitas karet. Media Perkebunan, 26-28.

Putri, F. D. A. (2016, 26 September). Tingkatkan pendapatan petani karet Sumut bentuk UPPB. Bisnis.com. Retrieved from http://industri.bisnis.com/read/20160926 /99/587028/tingkatkan-pendapatanpetani-karet-sumut-bentuk-uppb

Rosyid, M. J. (2014, Oktober). Karet Indonesia dilematis. Media Perkebunan, 34-35.

Solichin, M., Anwar, A., \& Tedjaputra, N. (2007). Penggunaan asap cair Deorub dalam pengolahan RSS. Jurnal Penelitian Karet, 25(1), 1-12.

Supriadi, M. (1990). Karakteristik inovasi usahatani karet. Lateks, 5(1), 1-7. 
Supriadi, M., \& Nancy, C. (2001). Analisis kelembagaan dan dinamika kelompok pada organisasi petani di kawasan industri masyarakat perkebunan (KIMBUN) Mesuji, Sumatera Selatan. Jurnal Penelitian Karet, 19(1-3), 32-53.

Syahza, A., Bakce, D., \& Hamlin, N. (2015). Strategi percepatan pembangunan ekonomi melalui penataan kelembagaan dan industri karet alam di Provinsi Riau. Riau, Indonesia: Lembaga Penelitian dan Pengabdian Masyarakat, Universitas Riau.

Syarifa, L. F., Agustina, D. S., \& Nancy, C. (2013). Evaluasi pengolahan dan mutu bahan olah karet rakyat (bokar) di tingkat petani karet di Sumatera Selatan. Jurnal Penelitian Karet, 31(2), 139-148.

Syarifa, L. F., Agustina, D. S., Nancy, C., \& Supriadi, M. (2012). Evaluasi tingkat adopsi klon unggul di tingkat petani karet propinsi Sumatera Selatan. Jurnal Penelitian Karet, 30(1), 12-22.

Syarifa, L. F., Hendratno, S., \& Agustina, D. S. (2010, 13-14 Desember). Efisiensi pemasaran bahan olah karet (BOKAR) dalam upaya meningkatkan harga petani karet di Sumatera Selatan. Paper presented at the Prosiding Seminar Nasional Hasil-Hasil Penelitian dan Pengkajian 2010, Palembang.
Testiana, R. (2010). Faktor-faktor yang mempengaruhi keputusan petani karet rakyat untuk mengikuti program revitalisasi perkebunan di Kec. Lubuk Batang Kab. OKU. AgronobiS, 2(3), 60-72.

Vachlepi, A., \& Solichin, M. (2008). Aplikasi formula asap cair (Deorub $\mathrm{K}$ ) sebagai penggumpal lateks. Warta Perkaretan, 27(2), 80-87.

Widyasari, T., \& Supriadi, M. (2008). Sistem alih teknologi karet: pengalaman malaysia. Warta Perkaretan, 27(2), 69-79.

Wulandari, D. (2014, 4 Juni). Sumsel didesak terapkan bokar bersih. Bisnis.com. Retrieved from http://kabar24.bisnis.com/ $\mathrm{read} / 20140604 / 78 / 233077 / \mathrm{sumsel}$ didesak-terapkan-bokar-bersih

Wulandari, D. (2015, 17 September). Peningkatan bahan olah karet kunci dorong daya saing. Bisnis.com. Retrieved from http://market.bisnis.com/read/20150917 /94/473368/peningkatan-bahan-olahkaret-kunci-dorong-daya-saing 